\title{
Obstacles for Innovative Activities in Lithuanian Low-tech Sector's Companies
}

\author{
Vitalija Venckuviene, dr. \\ Department of Economics \\ Kaunas University of Technology, Lithuania \\ Email: vitalija.venckuviene@ktu.It
}

Doi:10.5901/mjss.2014.v5n7p691

\begin{abstract}
The innovation concept seemed to be inherent in many fields of economy. Discourse in literature and policy formation level highlight the importance of high-tech sector as the innovation intensive one and concurrently leaving the low-tech sector aside. Still few studies provide evidences that low-tech sector's companies have potential to innovate (Hirsch-Kreinsen, Hahn and Jacobson, 2008, Cox, Frenz, and Prevezer, 2002, Santamaria et al., 2009, Heidenreich, 2009). Thus the paper aims to reveal the most inherent innovations in low-tech sector and identify the obstacles they face in introducing various types of innovations. The method of experts' evaluation was chosen in order to gather the experts' opinion about the specific issues on introduction of innovation in low-tech sector's companies in Lithuania. An interesting finding is that marketing, organisation and networking innovations' dimensions are considered not so inherent types of innovations as the product and technological innovations are. Considering the highly intensive competition in low-tech sector's markets the marketing strategies for creating new paths of innovations in this scope are extremely important. Also the paper discusses the main obstacles of innovative activities which were emphasized by experts.
\end{abstract}

Keywords: innovations, low-tech sector, experts' evaluation method, Lithuania

\section{Introduction}

Abundance of research in the scope of innovation especially in measurement systems justifies the importance of this phenomena and it seems that it is inherent in every level of economic life. Now it is agree that the innovation concept covers much more than just product and technology innovations. And moreover the discourse in literature considers rethinking of sectors classification because the evidence of various forms innovations are obvious in low-tech sector's industries (Hirsch-Kreinsen, Hahn and Jacobson, 2008, Cox et al., 2002, Santamaria et al., 2009, Heidenreich, 2009). Some research results indicate that product innovation is typically assigned to high technology industries (Cox et al., 2002). But process innovation is strong side in low-tech sector (Kirner, Kinkel and Jaeger, 2009). Heidenreich (2009) named "process, organisational and marketing innovations" as inherent innovations for low-tech sector's companies. Also the external source for innovation in low-tech sector are emphasized in several studies (Cox et al., 2002; Heidenreich, 2009), while high-tech sector's companies focus more on internal resources. Therefore this research covers mainly two important questions: 1) what are typical innovations in low tech sector; and 2) what are the main problems the low tech companies faces in the innovation implementation process.

Thus the paper aims to reveal the most inherent innovations in low-tech sector's companies and identify the obstacles they face in introducing various types of innovations.

In this paper low-tech sector refers to the industrial branches which focus on usage of traditional technologies specifically: wood and wood products and paper production, furniture production, and textile and the apparel production.

The paper is organised in the following manner: the second section presents the innovation's measurement aspects in low-tech companies; the third section reveals the methodology framework for this paper and the fourth section presents main results and discussion. Finally paper ends with conclusions.

\section{Measurement Features of Innovative Activities in Low-Tech Sector's Companies}

The innovation capability is recognized as one of the main aspects leading to a competitive advantage amongst firms. The literature review shows that approach to innovation concept has changed significantly over the time. Milbergs and Vonortas (2005) have identified four generations of innovation measurement system. First generation of innovation measurement system reflects the linear concept of innovation, which focuses on the cost of the process of innovation 
indicators. The second generation focuses on the innovation input indicators and connects innovation performance indicators. The third generation reveals a broader approach to innovation and focuses on regional innovation capacity studies, regional ranking. The fourth generation of innovation measurement system is named "embryonic" stage and it deals with the innovation process indicators (Milbergs \& Vonortas, 2005).

Research shows that innovation is a multifaceted concept and includes many business areas. Rogers (2004) investigates factors for introduction of new products, services or processes comparing manufacturing and nonmanufacturing firms. The findings show that for the manufacturing firms „innovation may be higher in exporting firms, firms with higher management training, firms that network, firms that conduct comparisons with other businesses, and firms that do R\&D; in contrast, foreign ownership may lower innovation." (Rogers, 2004).

According to Carney and Ryan (2010), measurement of innovation in different sectors needs for consideration of their specificities. They provide important aspects for 11 business sectors in measuring innovativeness. But the low-tech sector is not mentioned among these sectors. Regarding the high-tech manufacturing sector to measure innovativeness important aspect is "Strategic importance of innovation* -the extent to which strategic objectives have been met by the innovation" (Carney and Ryan, 2010). According to Carney and Ryan (2010), less important aspects are product advantage, innovativeness, financial performance and business performance (Carney \& Ryan, 2010).

Considering the sectors' taxonomy in terms of innovation intensive, some studies provide an alternative to the one that OECD presents. Gomes, Fornari and Morceiro (2013) suggest broadening the innovation measurement system involving "broad set of activities developed in the scope of the company, linked to the incremental innovation, social interaction, diversification, user -producer relation, some of them closely related to the diffusion of technology". For instance research on Italian sectors enabled to provide 5 subdivisions of industries in terms of channels and methods employed to introduce technological innovations (Archibugi, Cesaratto and Sirilli, 1991): (1) "Producers of traditional consumer goods", (2) "Suppliers of traditional intermediate goods", (3) "Specialized suppliers of intermediate goods", (4) "Mass-production assemblers" and (5) "R\&D based".

Zen, Reichert Quimi Pufal and Zawislak (2012) research concerning the changes in the low-tech sector's companies in Brazil revealed some interesting aspects, they contended that low-tech companies tend to innovate specifically "optimizing their processes and commercializing their products" and improving transactional capability i.e. "developing new forms to communicate and provide services to their clients".

Literature review indicates that in addition to such well-established innovation types, such as product, process innovation, marketing and organizational innovation, it is appropriate to distinguish and networking innovation meaning the environment that surrounds the companies (partners, clusters, technology platforms) in innovations emerging through this networks. While Tidd (2001) states that „A network is more than an aggregation of bilateral relationships or dyads, and therefore the configuration, nature and content of a network impose additional constraints and present additional opportunities".

Tello-Gamarra and Zawislak (2013) presents an innovation capability model which has two main capability drivers: a set of technological capabilities and a set of business capabilities. In this model, the technology drivers are represented by the technology development capability and the operational capability, and the business drivers are represented by the management capability and transaction capability.

Meanwhile the analysis of literature enabled to present a framework for internal factors for innovation creation potential in a company. This framework is applicable to various industries, but considering the heterogeneity aspects some factors weights can be increased and some decreased.

Strategic management is a starting point in seeking the higher innovativeness indicators in companies. The targets set in a top level of management influence the whole processes in a particular company. The human resource management embeds the main component of creativeness in an organization. The sufficient critical mass for the innovation creation is essential and the input needed for the development of this scope should be considered in more respectively.

Technological capacity shows the companies' ability to produce and to adapt to markets' needs. The timely technological development in a company may lift its competitive advantage in terms of satisfying customers' needs. Financial resources show ability of a company to react flexibly in dynamic environment. Networking ability in this paper refers to communication process in both internal network and external network as well. Marketing capacity means ability to manage the whole process of commercialisation of innovative products and to introduce quickly it in the market. In the framework presented below the learning process incorporates as a horizontal activity in an organisation. 
Figure 1. Internal factors for innovation creation potential framework

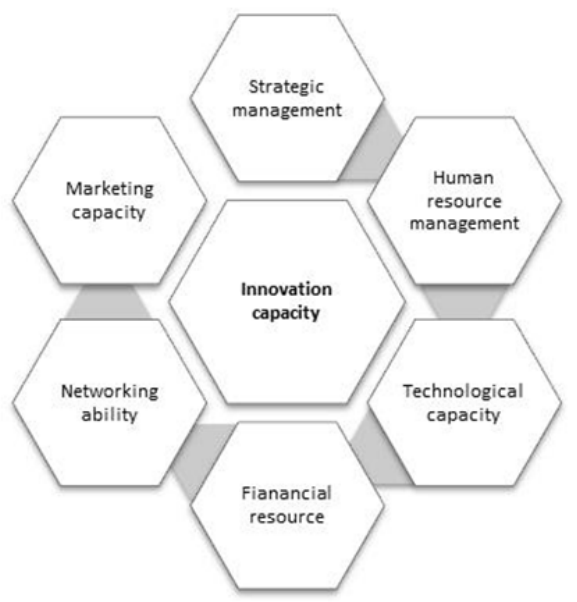

Source: Compiled by author.

To sum up innovation capacity in a particular company embeds various aspects. Empirical research shows different measurement systems for innovative activities in companies: starting from quantitative approaches to qualitative ones. The common measures in quantitative studies are investments in R\&D, and number of patents. Meanwhile qualitative approaches embed mainly case studies method. The qualitative approach leads to the deeper insight in to the analysing object. Therefore in the further analysis we are looking for innovations that are most common for low-tech sector and focusing on the obstacles they encounter introducing various types of innovation in terms of qualitative perspective.

\section{Methodology and Data}

\subsection{Methodology of empirical investigation of innovation activities in low-tech sector}

Expert evaluation method is justified in literature. Choosing the right experts is the core element seeking for research validity and reliability in expert evaluation research. The sample size for such type of research is not so necessary, according to Mason (2010) the data saturation fact is essential factor in determining the sample size of qualitative research.

The aim of this empirical research was to identify the inherent type of innovation and the obstacles associated with implementation of innovation in low-tech sector's companies based on experts' opinion.

In this paper we focus on the strengthening innovation capacity in low-tech sector in Lithuania. 26 out of 60 top managers from prominent low-tech sector's companies agreed to participate in the expert evaluation.

Thus this research covers mainly two important questions: 1) what are typical innovations in low tech sector; and 2) what are the main problems the low-tech companies' faces in the innovation implementation process.

The reliability of expert evaluation method is computed based on Cronbach's alpha (hereinafter alpha). Alpha is a popular coefficient of reliability, and is called a measure of internal consistency, which is based on inter-correlation for a set of variables (Gliem and Gliem, 2003). A high inter-correlation implicates that the data are unidimensional and measure the same construct (Yu, n.d.). It varies from 0 to 1, the alpha closer to 0 indicates low internal consistency, and vice versa - closer to 1 indicates a perfect relationship among the items, meaning the high internal consistency.

The agreement among the experts is measured using Kendall's concordance coefficient (hereinafter W), which is non parametric test and is based on Friedman test. "Kendall's W measures the extent to which the $\mathrm{N}$ judges agree on their rankings of the $\mathrm{K}$ applicants." (Mehta and Patel, 2011). And null hypothesis "that Kendall's coefficient of concordance is 0" (Mehta and Patel, 2011, p. 108) if the corresponding p-value is less than 0.05 the null hypothesis can be rejected. $W$ coefficient varies between 0 and 1 , "The scaling ensures that $W=1$ if there is perfect agreement among the $\mathrm{N}$ judges in terms of how they rank the K applicants." (Mehta and Patel, 2011, p. 109), and 0 indicates that there is no 
agreement among experts.

Factor analysis, specifically principal component analysis is employed with the aim to group main problems associated with innovation in fewer components. The research estimations are made in SPSS 17.0.

Of course one should consider the limitations of research presented in this paper:

1. The questionnaire was prepared based on literature review and personal implications;

2. The experts present a various industries, and the problems and types of innovation could vary among them.

\section{Finding and Discussion}

Demographic data of experts. The experience of experts is presented in fig. 2, which depicts that the majority of experts (73 percent) have more than 10 years experience in their work field. 19 percent of experts have experience from 5 to 10 years. Thus it is obvious that the majority of experts satisfy the main criteria in expert evaluation research.

Figure 2. The experience of experts.

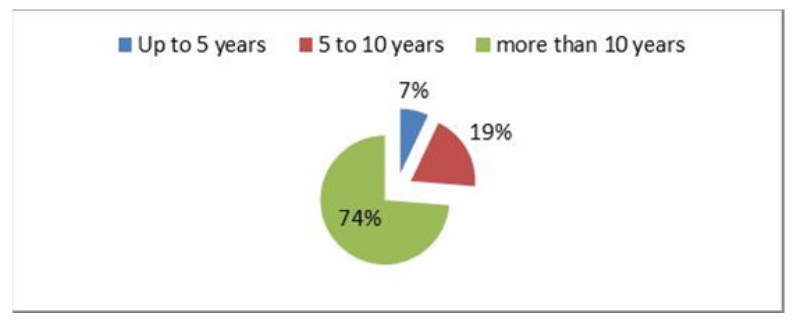

Figure 3 outlines percentage distribution of experts in terms of their representational sector. It is seen that experts distribute along the various branches of low tech sector. The majority of experts (35 percent) come from the apparel production, 19 percent of experts were representatives of furniture production industry and others.

Figure 3. Experts' distribution among sectors

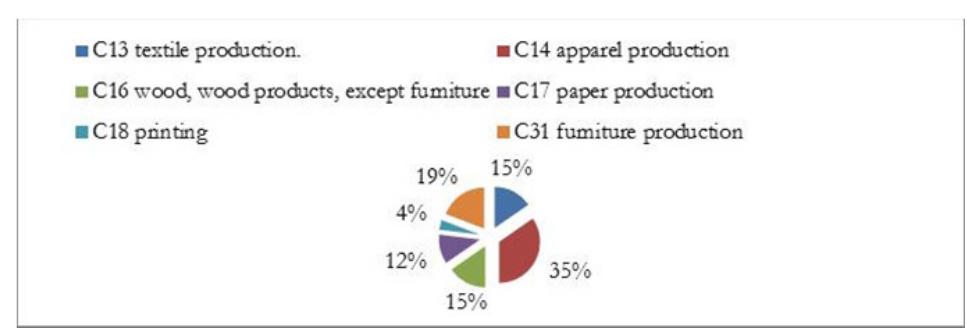

Inherent innovation in low-tech sector. The experts were asked to rate the most inherent type of innovations in their company/ sector. In this paper five main dimensions of innovation are analysed:

1. Product innovation are considered as new or improved products;

2. Technological innovation in terms of implementing new and/or improved technologies, in order to modern the production process and assimilation of novel technologies;

3. Organization innovation covers the new ways of management, quality standards, improvement of process management and others.

4. Marketing innovation embeds the commercialisation of products, new way of entry to market, new solutions for marketing and others.

5. Networking innovations refer the communication (internal and external) process in research, commercialisation process, projects and others.

Cronbach's alpha associated to this scale was 0.654 . It is slightly lower than recommended critical value 0.7 . Having in mind that the scales of items are only 5 elements this suggests that the alpha could suffer due to small item number. The deeper analysis of reliability shows that marketing innovation dimension have low inter item correlation, and 
it would be omitted the Cronbach's alpha could be 0.733 . For the further analysis we do not exclude marketing innovation dimension due to it argued importance in the literature.

Considering innovation typology in low tech companies in Lithuania the distribution of expert ratings (mean ranks) are presented in figure 4.

Figure 4. The most inherent types of innovations in low-tech sector (ratings presented in mean rank)

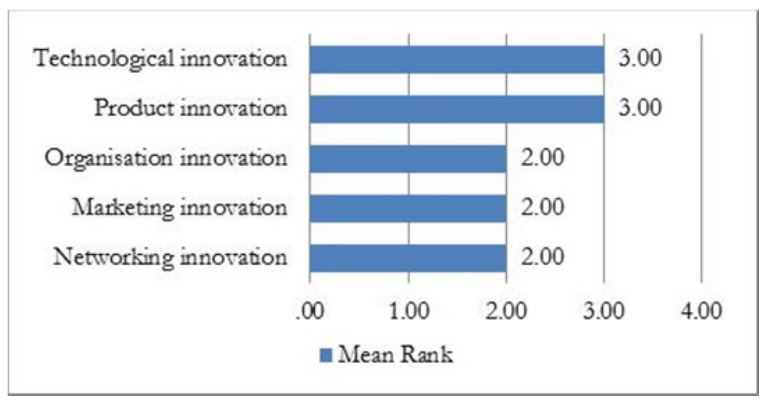

The research results indicate technological innovation and product innovation (mean rank 3.62) as most likely present (inherent) in their companies. The least mean rank was given for the networking, marketing and organisation innovations. In contrast Von Tunzelman and Acha (2005) highlight that low-tech sector "may place less emphasis on technology functions and more on product/marketing functions" comparing to high-tech sector's companies.

Mean ranks are presented based on Friedman test (Chi-Square values and corresponding $p$-value is presented in table 1 below. The Kendall's $W$ in this case is quite small -0.172 , but corresponding p-value $(0.001)$ indicates significance of the test. Although the $W$ is small indicating weak agreement of experts it implicates that maybe for experts there is not so much differences among the items presented for rating. This conclusion was verified with a Monte Carlo estimate of the exact $p$ value, based on 10,000 random combinations of the original two-way layout of mid-ranks. The Monte Carlo estimate is 0.001 and it is the same as computed asymptotic $p$-value $(0.003)$, and it suggest that the $W$ significant differ from 0.

Table 1. Kendall's test statistics

\begin{tabular}{|c|c|c|c|}
\hline \multicolumn{3}{|l|}{$\mathrm{N}$} & 26 \\
\hline \multicolumn{3}{|l|}{ Kendall's Wa } & 0.172 \\
\hline \multicolumn{3}{|l|}{ Chi-Square } & 17.851 \\
\hline \multicolumn{3}{|l|}{ df } & 4 \\
\hline \multicolumn{3}{|l|}{ Asymp. Sig. } & 0.001 \\
\hline \multirow[t]{3}{*}{ Monte Carlo Sig. } & Sig. & & $0.001^{b}$ \\
\hline & $99 \%$ Confidence Interval & Lower Bound & 0.000 \\
\hline & & Upper Bound & 0.002 \\
\hline
\end{tabular}

a. Kendall's Coefficient of Concordance

b. Based on 10000 sampled tables with starting seed 624387341.

For further analysis exploratory factor analysis is employed in order to cluster the dimensions in groups based on correlation. Kaiser-Meyer-Olkin Measure of Sampling Adequacy index is sufficient for factor analysis $(0.638>0.5)$, and $p$ value (sig. 0.008 ) is less than 0.05 , indicating that there is enough sample size for factors extraction.

Principal component analysis extracted two components, which explain almost 67 percent of variation (see table 2). Components are extracted based on critical Eigen value (higher than 1). $1^{\text {st }}$ component comprises 44.67 percent of variance, $2^{\text {nd }}$ component embeds 22.26 percent of variance (see table 2 ). 
Table 2. Kendall's test statistics

Total Variance Explained

\begin{tabular}{|c|c|c|c|c|c|c|c|c|c|}
\hline \multirow[b]{2}{*}{ Component } & \multicolumn{3}{|c|}{ Initial Eigenvalues } & \multicolumn{3}{|c|}{ Extraction Sums of Squared Loadings } & \multicolumn{3}{|c|}{ Rotation Sums of Squared Loadings } \\
\hline & Total & $\begin{array}{c}\% \text { of } \\
\text { Variance }\end{array}$ & $\begin{array}{c}\text { Cumulative } \\
\%\end{array}$ & Total & $\begin{array}{c}\% \text { of } \\
\text { Variance }\end{array}$ & $\begin{array}{c}\text { Cumulative } \\
\%\end{array}$ & Total & $\begin{array}{c}\% \text { of } \\
\text { Variance }\end{array}$ & $\begin{array}{c}\text { Cumulative } \\
\%\end{array}$ \\
\hline 1 & 2.234 & 44.678 & 44.678 & 2.234 & 44.678 & 44.678 & 2.233 & 44.657 & 44.657 \\
\hline 2 & 1.113 & 22.267 & 66.945 & 1.113 & 22.267 & 66.945 & 1.114 & 22.288 & 66.945 \\
\hline 3 & .815 & 16.299 & 83.245 & & & & & & \\
\hline 4 & .479 & 9.572 & 92.816 & & & & & & \\
\hline 5 & .359 & 7.184 & 100.000 & & & & & & \\
\hline
\end{tabular}

Extraction Method: Principal Component Analysis.

Rotation was made based on Varimax method, and in the Rotated Component Matrix (table 3 ) it is seen tha1 $1^{\text {st }}$ component covers 4 items (Product innovation, Technological innovation, Organisation innovation, and Networking innovation), meaning that those four dimension makes a group of items and can be considered as one component. Meanwhile Marketing innovation should be analysed apart, because it depends to $2^{\text {nd }}$ component.

Table 3. Kendall's test statistics

Rotated Component Matrix ${ }^{a}$

\begin{tabular}{|l|c|c|}
\hline \multirow{2}{*}{} & \multicolumn{2}{|c|}{ Component } \\
\cline { 2 - 3 } & 1 & 2 \\
\hline Product innovation & $\mathbf{0 . 6 8 3}$ & -0.230 \\
Technological innovation & $\mathbf{0 . 8 4 6}$ & -0.206 \\
Organisation innovation & $\mathbf{0 . 6 9 7}$ & 0.443 \\
Marketing innovation & -0.074 & $\mathbf{0 . 8 9 2}$ \\
Networking innovation & $\mathbf{0 . 7 4 8}$ & 0.164 \\
\hline
\end{tabular}

Extraction Method: Principal Component Analysis.

Rotation Method: Varimax with Kaiser Normalization.

a. Rotation converged in 3 iterations.

To summarise the innovation dimensions in low tech sector one can find interesting that marketing innovation are considered as not so inherent innovation type as the product and technological innovations are. Having in mind that the low tech sector's market is broad and full of competitors and therefore marketing strategies becomes a core element for increasing competitive advantage and new paths for innovations in this scope should be considered more carefully.

Obstacles for innovation implementation in low-tech sector. Analysis of problems which are faced by low tech companies in Lithuania is presented below. Six items were presented for experts to rank (in 5 point Likert scale, 1 meaning totally disagree and 5 indicating total agreement):

1. Huge innovation costs;

2. Uncertainty in the demand of innovative products;

3. Insufficient/ limited financial perspective for innovative activities;

4. Insufficient technological base;

5. Insufficient potential of human resource (capabilities, creativeness) and lack of motivation;

6. Insularity of companies and lack of collaboration with innovation partners.

Table outlines the Reliability Statistics of items presented above. Estimated alpha equals to 0.823 , indicating good internal consistency.

Having in mind that Cronbach's alpha is sensitive to the number of items in the scale and in the present analysis there are only 6 items, it suggests that the items in the scale are highly correlated. 
While analysing the agreement among the experts quite small $W(0.138)$ was computed, also $p$-value $(0.003$ $<0.05)$ indicates the significance of the test. This conclusion was verified with a Monte Carlo estimate. The Monte Carlo estimate is 0.002 , less than the asymptotic $p$ value (0.003), and it suggests that the $W$ is significant different from 0 .

Table 4. Kendall's test statistics

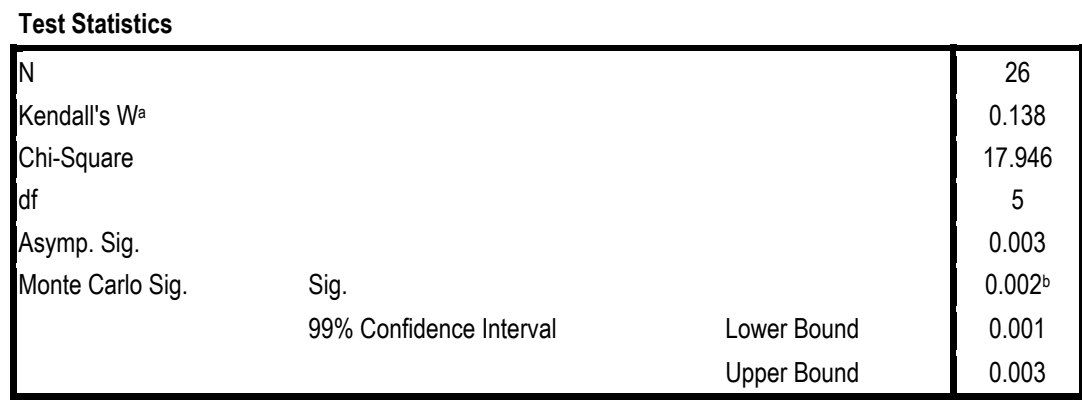

a. Kendall's Coefficient of Concordance

b. Based on 10000 sampled tables with starting seed 926214481.

When analysing experts ratings, the figure 5 depicts that the most significant problems for implementing innovations are basically two (Huge innovation costs - mean rank of 4.33; and Insufficient/ limited financial perspective for innovative activities - mean rank of 3.92), while the least significant problem was identified the category - "Insufficient technological base", which implicates that experts' are quite sure about the sufficient technological level in their companies.

Figure 5. The most inherent type of innovation in low tech sector (ratings presented in mean rank)

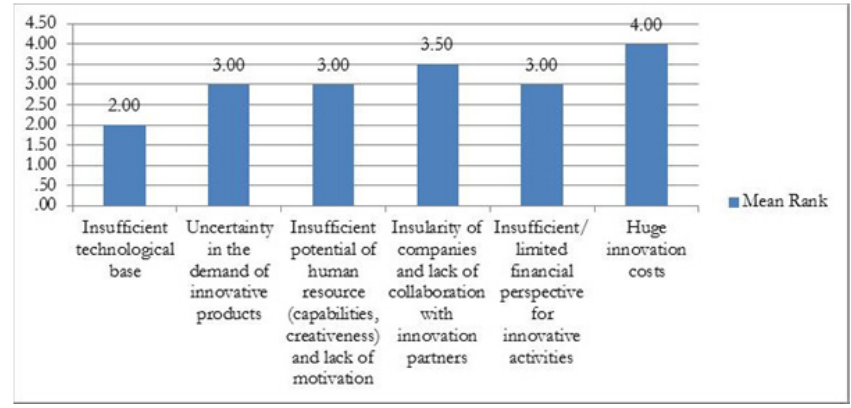

Considering factor analysis for grouping the presented problems into fewer groups, the KMO and Bartlett's Test's results presented below in the table, indicating the sufficient sample size for the extracted components. KMO index is more than sufficient $(0.719>0.5$ ), and p-value (sig. 0.000 ) is less than 0.05 , indicating that there is enough sample size for factors extraction.

Table 5. Kendall's test statistics

KMO and Bartlett's Test

\begin{tabular}{|c|c|c|}
\hline \multicolumn{2}{|c|}{ Kaiser-Meyer-Olkin Measure of Sampling Adequacy. } & 0.719 \\
\hline \multirow[t]{3}{*}{ Bartlett's Test of Sphericity } & Approx. Chi-Square & 57.698 \\
\hline & $d f$ & 15 \\
\hline & Sig. & 0.000 \\
\hline
\end{tabular}


Principal component analysis extracted two components, which accounts for 72.59 percent of variation (see table 6). $1^{\text {st }}$ component comprises 53.96 percent of variance, $2^{\text {nd }}$ component embeds 18.62 percent of variance (see table 6 ).

Table 7. Total Variance Explained

\begin{tabular}{|c|c|c|c|c|c|c|c|c|c|}
\hline \multirow{2}{*}{ Component } & \multicolumn{3}{|c|}{ Initial Eigenvalues } & \multicolumn{3}{|c|}{ Extraction Sums of Squared Loadings } & \multicolumn{3}{|c|}{ Rotation Sums of Squared Loadings } \\
\cline { 2 - 9 } & Total & $\%$ of Variance & Cumulative \% & Total & $\%$ of Variance & Cumulative \% & Total & $\%$ of Variance & Cumulative \% \\
\hline 1 & 3.238 & 53.968 & 53.968 & 3.238 & 53.968 & 53.968 & 2.410 & 40.162 & 40.162 \\
2 & 1.117 & 18.624 & 72.592 & 1.117 & 18.624 & 72.592 & 1.946 & 32.429 & 72.592 \\
3 & .658 & 10.971 & 83.563 & & & & & & \\
4 & .428 & 7.135 & 90.698 & & & & & & \\
5 & .352 & 5.859 & 96.556 & & & & & & \\
6 & .207 & 3.444 & 100.000 & & & & & & \\
\hline
\end{tabular}

Extraction Method: Principal Component Analysis.

Based on rotation (see Rotated Component Matrix, table 7) it is seen that $1^{\text {st }}$ component covers 4 items all of them are related to uncertainty and risk associated to innovation performance in terms of financial resources. While $2^{\text {nd }}$ component embeds two items which are related to the lack of potential for innovative activities in more "soft" perspective concerning the human resource potential and company's potential for networking.

Table 7. Rotated Component Matrix ${ }^{a}$

\begin{tabular}{|l|c|c|}
\hline & \multicolumn{2}{|l|}{ Component } \\
\cline { 2 - 3 } & 1 & 2 \\
\hline Huge innovation costs & $\mathbf{0 . 7 4 1}$ & 0.409 \\
Uncertainty in the demand of innovative products & $\mathbf{0 . 8 4 2}$ & -0.052 \\
Insufficient limited financial perspective for innovative activities & $\mathbf{0 . 8 4 1}$ & 0.230 \\
Insufficient technological base & $\mathbf{0 . 6 1 8}$ & 0.565 \\
Insufficient potential of human resource (capabilities, creativeness) and lack of motivation & 0.038 & $\mathbf{0 . 8 5 7}$ \\
Insularity of companies and lack of collaboration with innovation partners & 0.245 & $\mathbf{0 . 8 1 8}$ \\
\hline
\end{tabular}

Extraction Method: Principal Component Analysis.

Rotation Method: Varimax with Kaiser Normalization.

a. Rotation converged in 3 iterations.

Analysing experts' attitudes towards the problems that are faced in low -tech sector's companies two interesting dimensions were revealed. On the one hand companies struggle with uncertainty and risk for default because innovations are characterised by having high cost, uncertainty in demand, limited financial opportunities, and insufficient technological base (also it indicates about the huge investments).

On the other hand experts' evaluation method revealed that there are more in-depth problems concerning the innovation implementation in low-tech sector. For instance two items (Insufficient potential of human resource (capabilities, creativeness) and lack of motivation; and Insularity of companies and lack of collaboration with innovation partners) could be analysed together as one component, and in the future research there could be more in-depth analysis concerning investigation of detail constituents of these two dimensions.

\section{Conclusions}

Innovations are considered as the main potential for growth and competitiveness. There is no doubt that innovation phenomena should be analysed in a complex system, because of the multidimensionality of innovations.

The article was aimed at the identification of inherent innovation dimensions in Lithuania's manufacturing industry, 
specifically low-tech sector (wood and wood products and paper production, furniture production, and textile and the apparel production). Research has revealed most common types of innovations. The highest mean ranks were computed for the product and technological innovation. The interesting finding is that marketing innovation dimension is considered as not so inherent innovation type as the product and technological innovations are. Having in mind that there is intensive competition in low-tech sector's market and highly dependent on price and quality factors, therefore the marketing strategies, for new paths on innovations in this scope should be considered more carefully. On the other hand maybe the dimensions of innovations like marketing, organisation and networking are not vital in practices and it is difficult to identify them at a company's level.

\section{Acknowledgement}

The author acknowledge the funding of The Research Council of Lithuania to make the research by project No. IEP01/2012.

\section{References}

Archibugi, D., Cesaratto, S., and Sirilli, G. (1991). Sources of innovative activities and industrial organization in Italy. Research Policy 20 (1991) 299-313. http://www.danielearchibugi.org/downloads/papers/Archi_Cesa_Siri_RP.pdf

Carney, P., \& Ryan, M. (2010). Measuring firm-level Innovation: Review of the Literature \& Survey-design. UCD Geary Institute. Final version, 6th November 2010. [žiureta 2012-08-29]. Prieiga per Interneta: <http://www.innovationfoundation.ie /lrish\%20Innovation\%20Index\%20Background.pdf>.

Cox, H., Frenz, M., Prevezer, M. (2002). Patterns of innovation in UK industry: exploring the CIS data to contrast high and low technology industries. Journal of Interdisciplinary Economics, 13 (1) (2002), pp. 267-304. Retrieved from http://eprints.worc.ac.uk/223/1/Patterns_of_innovation.pdf

Gliem, J. A., \& Gliem, R. R. (2003). Calculating, Interpreting, and Reporting Cronbach's Alpha Reliability Coefficient for Likert-Type Scales. 2003 Midwest Research to Practice Conference in Adult, Continuing, and Community Education. Retrieved from https://scholarworks.iupui.edu/bitstream/handle/1805/344/Gliem\%20\&\%20..?sequence=1

Gomes, R., Fornari, V.C. B., Morceiro, P. C. (2013). Innovative Activities in "Low and Medium - Low" Technology Industries: A survey on the mechanisms of diffusion of innovation. Retrieved from http://www.altec2013.org/programme_pdf/254.pdf

Guest, G., Bunce, A., \& Johnson, L. (2006). How Many Interviews Are Enough? Field Methods, 18(1), $59-82$.

Heidenreich, M. (2009). Innovation Patterns and Location of European Low- and Medium-Technology Industries. Research Policy, Volume 38, Issue 3, p.483-494. http://dx.doi.org/10.1016/..respol.2008.10.005.

Hirsch-Kreinsen, H., Hahn, K., Jacobson, D. (2008). The low-tech issue: Introduction. In H.Hirsch-Kreinsen, D.Jacobson (Eds), Innovation in Low-Tech Firms and Industries. (pp. 3-25). Retrieved from http://f3.tiera.ru/1/genesis/655659/655000/a096a5b7c066b1dee6c3cf1ca80b8f6b

http://itec.vru.ac.th/Industry001/\%B9\%C7\%D1\%B5\%A1\%C3\%C3\%C1/IM.pdf

Kirner, E., Kinkel, S. and Jaeger, A. (2009). Innovation paths and the innovation performance of low-technology firms-An empirical analysis of German industry. Research Policy, Volume 38, Issue 3, April 2009, p. 447-458. http://dx.doi.org/10.1016/j.respol.2008.10.011

Lewis, G.H., and Johnson, R.G. (1971). Kendall's Coefficient of Concordance for Sociometric Rankings with Self Exclude. Sociometry, Vol. 34, No. 4 (Dec., 1971), pp. 496-503. Retrieved from www.statpt.com/correlation/lewis_johnson_1971.pdf

Mason, M. (2010). Sample Size and Saturation in PhD Studies Using Qualitative Interviews. Forum Qualitative Sozialforschung / Forum: Qualitative Social Research; Vol 11, No 3 (2010): Methods for Qualitative Management Research in the Context of Social Systems Thinking. Retrieved from http://www.qualitative-research.net/index.php/fqs/article/view/1428/3027

Mehta, C.R., and Patel, N.R. (2011). IBM SPSS Exact Tests. Retrieved from http://www.csun.edu/sites/default/files/exact-tests2032bit.pdf

Milbergs, E., \& Vonortas, N., (2005). Innovation Metrics: Measurement to Insight. White Paper prepared for: National Innovation Initiative 21st Century Innovation Working Group. [žiürèta 2012-09-05]. Prieiga per internetą: <http://www.innovationmanagement.se/wpcontent/uploads/pdf/Innovation-Metrics-NII.pdf>.

Rogers, M. (2004). Networks, Firm Size and Innovation. Small Business Economics 22: 141-153, 2004. Retrived from http://download.springer.com/static/pdf/572/art\%253A10.1023\%252FB\%253ASBEJ.0000014451.99047.69.pdf?auth66=1397720 461_bce5c7281698a1c681692ab152db12dd\&ext=.pdf

Santamaría, L., Nieto, M. J., \& Barge-Gil, A. (2009). Beyond formal R\&D: Taking Advantage of Other Sources of Innovation in Low- And Medium-Technology Industries. Research Policy, Volume 38, Issue 3, p.507-517. http://dx.doi.org/10.1016/j.respol.2008.10.004

Santamaría, L., Nieto, M. J., \& Barge-Gil, A. (2009). Beyond formal R\&D: Taking Advantage of Other Sources of Innovation in Low- And Medium-Technology Industries. Research Policy, Volume 38, Issue 3, p.507-517. http://dx.doi.org/10.1016/j.respol.2008.10.004

Tello-Gamarra, J., Zawislak, P.A. (2013). Transactional capability: Innovation's missing link. J. econ. finance adm. sci, 18(34), 2013, 2-8. http://www.ungs.edu.ar/globelics/wp-content/uploads/2011/12/ID-284-Tello-Gamarra-Zawislak-Alves-Barbieux-Reichert- 
Innovation-policies.pdf

Tidd, J. (2001). Innovation management in context: environment, organization and performance. International Journal of Management Reviews Volume 3 Issue 3 pp. 169 -183. Retrieved from

Von Tunzelman, N., Acha, V. (2005). Chapter 15: Innovation in "low-tech" industries. In J.Fagerberg, D.C. Mowery, R.R. Nelson (Eds), The Oxford Handbook of Innovation, Oxford University Press, Oxford, pp. 407- 433.

$\mathrm{Yu}, \mathrm{Ch}$. H. (n.d.). An introduction to computing and interpreting Cronbach Coefficient Alpha in SAS. Statistics data analisys and data mining. Paper 246-26. Retrieved from http://www2.sas.com/proceedings/sugi26/p246-26.pdf

Zen, A.C., Reichert, F.M., Quimi, L.D.S., Pufal, N.A., and Zawislak, P.A. (2012). Types of Innovation in Low-Technology Companies Of Emerging Markets: An Empirical Study In Brazilian Industry. Retrieved from http://www.anpad.org.br/diversos/trabalhos /Simp\%C3\%B3sio/simposio_2012/2012_SIMPOSI0195.pdf 